\title{
Derivatives of Phenylene-1,2-diamine as Modifiers for Unsaturated Polyester Resins
}

\author{
Renata Lubczak* and Jerzy Duliban \\ Rzeszów University of Technology, Department of Organic Chemistry, Faculty of Chemistry, \\ Al. Powstańców Warszawy 6, 35-959 Rzeszów, Poland \\ *Corresponding author: E-mail: rlubczak@prz.edu.pl
}

Received: 06-30-2019

\begin{abstract}
The results are presented on the synthesis of new modifiers for unsaturated polyester resins, obtained by reacting ethylene oxide or propylene oxide with phenylene-1,2-diamine. The effect of the modifiers and cobalt accelerator on the reactivity of resins was also studied. When used in the amount of up to $1.50 \mathrm{wt} . \mathrm{-} \%$, the amines substantially (several times) reduced the gelation time of modified unsaturated polyesters. The reactivity of resins, however, improved on the expense of their stability.
\end{abstract}

Keywords: Unsaturated polyester resins; amine modifiers; modification of polyester resins

\section{Introduction}

Unsaturated polyesters are most frequently obtained from equimolar amounts of maleic anhydride and phthalic anhydride. Their curing is carried out in copolymerization reactions with vinyl monomers, mostly with styrene. A solution of a polyester in such monomer is called polyester resin. Copolymerization is most frequently carried out as radical reaction initialized with hydroperoxides, peroxides of ketones and acyl peroxides, most commonly benzoyl peroxide. Most of peroxide initiators require elevated temperature in order to start the curing process. To reduce the activation energy of decomposition of peroxides, polymerization accelerators called pre-accelerators are used to cause commencement of the curing reaction, sometimes even at a temperature of $5{ }^{\circ} \mathrm{C} .{ }^{1}$ Such accelerators include amine compounds. These compounds were initially introduced into the system before the start of the curing process. To avoid dosing the accelerator as a separate packaging, manufacturers began to mix accelerators with unsaturated polyester resin in the production process. Aromatic amines, such as $\mathrm{N}, \mathrm{N}$-dialkyl derivatives of aniline or $\mathrm{pa}$ $r a$-toluidine are most frequently used, as they dissolve in the resin component. Unfortunately, unsaturated resins with amine dissolved in them have poor shelf stability. ${ }^{1}$ The disadvantage of this procedure is the deactivation of the pre-introduced accelerator as well as its separation in the form of a separate phase upon long-term storage of the resin. Resins with chemically incorporated accelerators are characterized by better properties, among others because the accelerator is then evenly distributed in the polyester chain. Some initial information on this topic appeared in 1956 and was related to the incorporation of 2-hydroxyalkyl derivative of aniline (3-phenyl-3-azapentane-1,5-diol) ${ }^{2}$ into the resin structure, which partly replaced diethylene glycol used for the synthesis.

In turn, Li completely replaced glycol with the above mentioned compound, obtaining a resin with a high water resistance. ${ }^{3}$ In the following years, esters and diesters of aromatic acids substituted at the meta or para position with tertiary amine were used as pre-accelerators. To ensure their incorporation into the polyester structure they were subjected to transesterification of glycol, followed by reactions with maleic and phthalic anhydrides. ${ }^{4,5}$ Detailed comparative studies on the activity of amine pre-accelerators incorporated into polyester resin and those added as separate ingredients were performed by Jada in the late 1970 s and the early 1980 s. $^{6-8} \mathrm{He}$ found out that resins with incorporated amines exhibited better mechanical properties and a higher thermostability. Jada also described the effect of a metal or amine incorporated into a polyester chain during the polycondensation reaction. ${ }^{78}$ Accelerators of the curing are compounds containing metals, e.g. vanadium and cobalt salts, of which the most popular are cobalt(II) naphthenates and 2-ethylhexanoates. Incorporation into the polyester chain of a metal in the form of dimaleate or acetate, cobalt, nickel or manganese in amounts higher than 0.25 mole resulted in curing of the 
product during its synthesis. The efficiency of their accelerating effect varied as follows: $\mathrm{Co}>\mathrm{Mn}>\mathrm{Ni}$. The curing takes place at 20 to $100^{\circ} \mathrm{C}$ when solution of cobalt(II) octanate or naphthenate is used. For fast gelation at room temperature, vanadium accelerators are used. Manganese accelerators with ketone peroxides or hydroperoxides yield unsaturated polyester compositions of long life time, but cure quickly at $60-100{ }^{\circ} \mathrm{C} .{ }^{1}$ Incorporation of cobalt(II) ions into the resin structure is described in a patent. ${ }^{9} \mathrm{Co}-$ balt(II) hydroxide was introduced into the unsaturated polyester obtained in reactions of ethylene and propylene glycol with phthalic and maleic anhydrides. The reaction mixtures were held at $140{ }^{\circ} \mathrm{C}$ until hydroxide has completely reacted. Finally, the polyester with the incorporated cobalt was dissolved in styrene.

Currently, traditional methods for pre-acceleration of polyester resins presented here are still in use, i.e. by mixing the accelerator with the resin before curing, ${ }^{10,11}$ but methods of obtaining stable solutions of accelerators applicable for storage ${ }^{12-14}$ are described increasingly often. Furthermore, studies on incorporation of pre-accelerators into the structure of polyester resins are still carried out. In a publication, ${ }^{15}$ the synthesis and the effect of amine modifiers obtained in the reactions of ethylene oxide or propylene oxide with $N, N^{3}$-diphenyletane-1,2-diamine and in the reactions of ethylene oxide with $N, N^{\prime}$-diphenylhexane-1,6-diamine are described. It was found out that using up to 2 wt.- $\%$ of these pre-accelerators reduces curing time of the resins by several times when compared to non-pre-acceler- ated resins. In turn, another publication ${ }^{16}$ describes the reaction between $N, N$-dimethyl-para-phenylenediamine and ethylene or propylene oxide which were carried out to obtain 3-[para-( $N, N$-dimethylamino)phenyl]-3-azapentane-1,5-diol and 4-[para-( $N, N$-dimethylamino)phenyl]4-azaheptane-2,6-diol, respectively. Prepared diols were incorporated into unsaturated polyester resins. The effect of concentration of the built-in pre-accelerator, the gelation rate and resin stability were investigated.

The results of the study on the activity of amine modifiers for unsaturated polyester resins obtained by reaction of diethanolamine (3-azapentane-1,5-diol) and $\mathrm{N}$-phenyl-2-aminoethanol with 2,4-dichloro-6-methoxy1,3,5-triazine, 2-chloro-4,6-dimethoxy-1,3,5-triazine or with cyanuric chloride are presented in the literature. ${ }^{17-19}$ Effects of the type and amount of amine modifier (in the amount of 0.25 to $2.0 \mathrm{wt} .-\%$ ), as well as cobalt accelerator on gelation time and stability of the resins were investigated. The effect of the presence of a modifier on the curing behavior of the resulting resin was discussed. In publications ${ }^{20,21}$ obtaining of the pre-accelerators by reaction of ethylene oxide or propylene oxide with phenylene-1,4-diamine and with phenylene-1,3-diamine were presented.

This paper describes the synthesis of pre-accelerators hydroxyalkylation reactions of phenylene-1,2-diamine with ethylene oxide and propylene oxide. Their pre-accelerating properties were analyzed and compared with the properties of hydroxyalkyl derivatives of phenylene-1,4-diamine and phenylene-1,3-diamine.

Table 1. Compounds Used and Their Suppliers.

\begin{tabular}{ll}
\hline Compound & Supplier \\
\hline $\begin{array}{l}\text { Accelerator Co-1 (1.0 wt.-\% solution of cobalt(II) } \\
\text { 2-ethylhexanoate in styrene) }\end{array}$ & ORGANIKA-SARZYNA, Nowa Sarzyna, Poland \\
\hline Benzyltriethylammonium chloride & $\begin{array}{l}\text { Prepared from trietylamine and benzyl chloride, University } \\
\text { of Technology, Faculty of Chemistry }\end{array}$ \\
\hline Hydroquinone, pa & POCH, Gliwice, Poland \\
\hline $\begin{array}{l}\text { Luperox K-1, (50 wt.-\% solution of peroxide of butanone } \\
\text { in dibutyl 1,2-phthalate) }\end{array}$ & ATOCHEM GmbH, Germany \\
\hline $\begin{array}{l}\text { Interox BP-50-P1, 50 wt.-\% solution of benzoyl peroxide } \\
\text { in dibutyl 1,2-phthalate }\end{array}$ & Peroxid Chemie GmbH, Germany \\
\hline Phthalic anhydride, pure & NITROGEN PLANTS Kędzierzyn, Poland \\
\hline Maleic anhydride, pure & NITROGEN PLANTS Kędzierzyn, Poland \\
\hline 3-Oxapentane-1,5-diol (diethylene glycol), pure & OIL REFINERY, Płock, Poland \\
\hline Propane-1,2-diol (propylene glycol), pure & OIL REFINERY, Płock, Poland \\
\hline Ethylene oxide, pure & Honeywell Research Chemicals, USA \\
\hline \begin{tabular}{l} 
\pm )Propylene oxide, pure \\
\hline Phenylene-1,2-diamine, pure
\end{tabular} & Honeywell Research Chemicals, USA \\
\hline Styrene, pure & SIGMA-Aldrich Chemical, Germany \\
\hline
\end{tabular}




\section{Experimental Section}

\section{1. Materials}

Table 1 presents a list of the materials used including their suppliers.

\section{2. Synthesis}

\section{2. 1. Synthesis of Benzene-1,2-diamine- $N, N, N^{`}, N^{`}$ -tetraethane-2,2',2“,2“'-tetraol (Modifier A) and Benzene-1,2-diamine- $N, N, N^{`}, N^{`}$ - tetrapropane-2,2,2“,2“-tetraol (Modifier B)}

To a $100 \mathrm{~mL}$ pressure reactor equipped with a magnetic stirrer $16.20 \mathrm{~g}(0.15 \mathrm{~mol})$ of phenylene-1,2-diamine was placed together with $26.45 \mathrm{~g}(44.05 \mathrm{~mL}, 0.60 \mathrm{~mol})$ of ethylene oxide or $34.85 \mathrm{~g}(42.0 \mathrm{~mL}, 0.60 \mathrm{~mol})$ of propylene oxide. The content was gradually heated to ca. $95^{\circ} \mathrm{C}$ while stirring. The temperature slightly increased as the reaction progressed. It was halted when temperature reached $100^{\circ} \mathrm{C}$. The time of the process was ca. 88 hours for the reaction with ethylene oxide or 95 hours for the reaction with propylene oxide. It was ended when the epoxide number of the reaction mixture was zero. The products of the reaction of phenylene-1,2-diamine with ethylene oxide or propylene oxide had a form resinous mass of dark brown color. Due to the presence of four active hydrogen atoms in the amino groups per $1 \mathrm{~mol}$ of the phenylene-1,2-diamine, $4 \mathrm{~mol}$ of oxirane were used without any solvent, so the provided products did not have to be isolated from the reaction mixture and as such they were used for polycondensation reactions in the obtained form, hence their yield was $100 \%$. The reaction products of phenylene-1,3-diamine and -1,4-diamine with oxiranes were obtained in the same yield..$^{20,21}$

The spectra of the substrate of phenylene-1,2-diamine are presented in Figs. 1 and 2, and the description of absorption IR spectra and resonance signals from ${ }^{1} \mathrm{H}$ NMR are presented in Tables 2 and 3. The chemical structure of the products was confirmed by elemental analysis (Table 4) and by spectroscopic methods: FT-IR (Table 2, Fig. 1) and ${ }^{1} \mathrm{H}$ NMR (Table 3, Fig. 2).
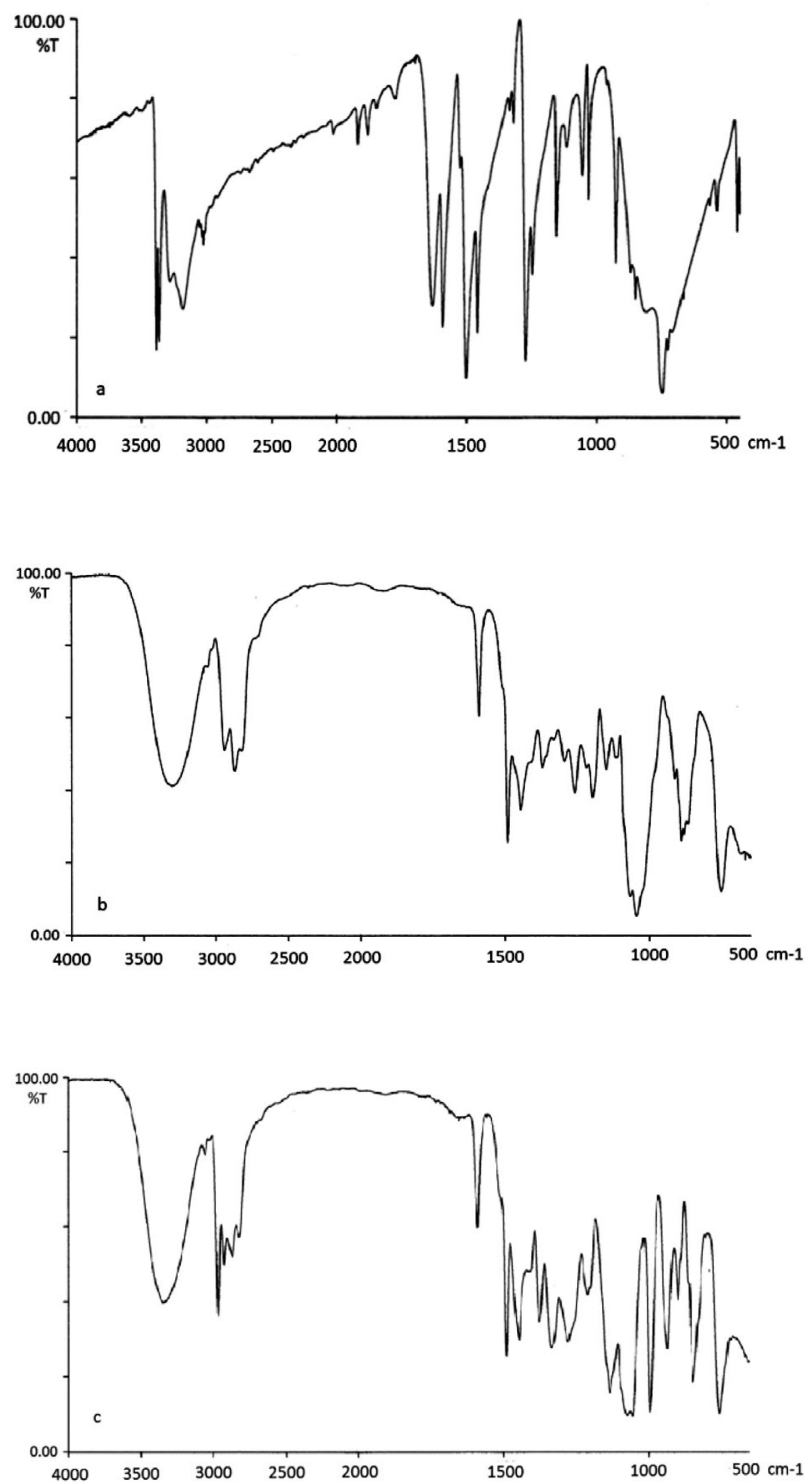

Figure 1. IR spectra of phenylene-1,2-diamine (a), benzene-1,2-diamine- $N, N, N, N$ '-tetraethane-2,2',2,2"'-tetraol (modifier A) (b), and benzene-1,2-diamine- $N, N, N, N^{\prime}$-tetrapropane-2,2',2",2"'-tetraol (modifier B) (c).

Table 2. Absorption Bands in IR Spectra of Phenylene-1,2-diamine and obtained Modifiers

\begin{tabular}{lccc}
\hline Type of vibrations and functional group & Phenylene-1,2-diamine & $\begin{array}{c}\text { Band location } \mathbf{( c m}^{-\mathbf{1}} \text { ) } \\
\text { Modifier A }\end{array}$ & Modifier B \\
\hline $\boldsymbol{v}_{\mathrm{NH} 2}$ & $3386,3364,3283,3185$ & - & - \\
$\boldsymbol{v}_{\mathrm{OH}}$ & - & 3306 & 3338 \\
$\boldsymbol{v}_{\mathrm{C}-\mathrm{H}}$ in aromatic ring & $3055,3043,3015$ & 3031 & 3061,3030 \\
$\boldsymbol{v}_{\mathrm{CH} 3}, \boldsymbol{v}_{\mathrm{CH} 2}$ & - & $2944,2873,2824^{\star}$ & $2966,2930,2877,2823$ \\
$\boldsymbol{v}_{\mathrm{C}=\mathrm{C},}$ aromatic ring vibrations & $1633,1592,1501$ & $1653,1590,1491$ & 1647,1590 \\
$\boldsymbol{\delta}_{\mathrm{CH} 3}, \boldsymbol{\delta}_{\mathrm{CH} 2}$ & - & $1447,1418,1372,1334$ & $1491,1448,1416,1374,1335$ \\
$\boldsymbol{\delta}_{\mathrm{NH} 2}$ & $1458,1321,1274,1248$ & - & - \\
$\boldsymbol{\delta}_{\mathrm{OH}}$ & - & 1150 & 1133 \\
$\boldsymbol{v}_{\mathrm{C}-\mathrm{O},}$ in first or second order alcohol & - & 1067,1044 & 1072,1054 \\
$\boldsymbol{\delta}_{\text {out of plane, aromatic ring vibrations }}$ & $928,872,852,808,748,712$ & $898,886,868,753$ & $995,933,899,847,755$ \\
\hline
\end{tabular}

${ }^{*}$ No bands for $\boldsymbol{v}_{\mathrm{CH} 3}$ or $\boldsymbol{\delta}_{\mathrm{CH} 3}$ are observed for this compound. 
Table 3. Chemical Shifts of Protons in ${ }^{1} \mathrm{H}$ NMR Spectra of Phenylene-1,2-diamine and obtained Modifiers

\begin{tabular}{|c|c|c|}
\hline Name of chemical compound & Chemical shifts ( $\delta$ ppm) & Group \\
\hline Phenylene-1,2-diamine & $\begin{array}{l}4.36 \\
6.37 \text { and } 6.48\end{array}$ & $\begin{array}{l}-\mathrm{NH}_{2} \\
\text { Aromatic protons }\end{array}$ \\
\hline $\begin{array}{l}\text { Benzene-1,2-diamine- } N, N, N^{\varsigma}, N^{\varsigma} \text {-tetraethane } \\
-2,2^{`}, 2^{“}, 2^{\prime \prime} \text {-tetraol (modifier A) }\end{array}$ & $\begin{array}{c}3.19 \\
3.40 \\
4.53 \\
6.85-7.10\end{array}$ & $\begin{array}{c}-\mathrm{CH}_{2}-\mathrm{O}- \\
-\mathrm{CH}_{2}-\mathrm{N}< \\
-\mathrm{OH} \\
\text { Aromatic protons }\end{array}$ \\
\hline $\begin{array}{l}\text { Benzene-1,2-diamine- } N, N, N, N^{\prime} \text {-tetrapropane-2,2',2",2"' } \\
\text {-tetraol (modifier B) }\end{array}$ & $\begin{array}{c}0.95 \text { and } 0.96 \\
0.97 \text { and } 0.98 \\
2.80-3.35 \\
3.65 \\
4.47 \text { and } 4.52 \\
4.90 \text { and } 5.18 \\
6.80-7.10\end{array}$ & $\begin{array}{c}-\mathrm{CH}_{3} \text { normal product } \\
-\mathrm{CH}_{3} \text { anomal product } \\
>\mathrm{N}-\mathrm{CH}_{2}-\mathrm{C} \\
>\mathrm{CH}-\mathrm{O}- \\
-\mathrm{OH} \text { normal product } \\
-\mathrm{OH} \text { anomal product } \\
\text { Aromatic protons }\end{array}$ \\
\hline
\end{tabular}

Table 4. Elemental Analysis of Modifiers

\begin{tabular}{lcccccr}
\hline Compound & \multicolumn{2}{c}{ \%C } & \multicolumn{2}{c}{ \%H } & \multicolumn{2}{c}{ \%N } \\
& Calcd. & Found & Calcd. & Found & Calcd. & Found \\
\hline Modifier A & 59.14 & 59.25 & 8.51 & 8.43 & 9.85 & 9.78 \\
Modifier B & 63.56 & 63.74 & 9.41 & 9.27 & 8.23 & 8.15 \\
\hline
\end{tabular}
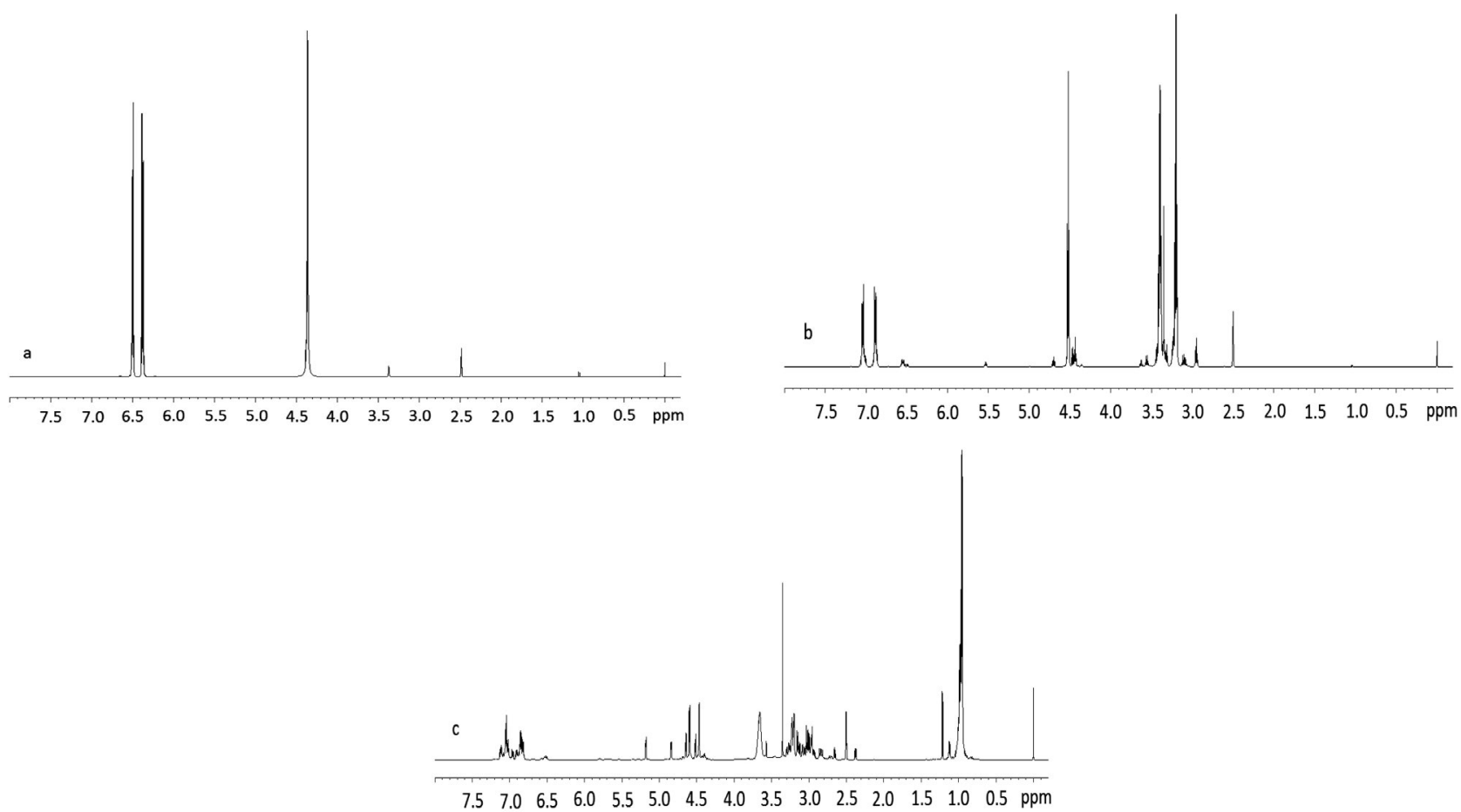

Figure 2. ${ }^{1} \mathrm{H}$ NMR spectra of phenylene-1,2-diamine (a), benzene-1,2-diamine- $N, N, N, N$-tetraethane-2,2',2",2"'-tetraol (modifier A) (b), and benzene-1,2-diamine- $N, N, N, N$ 'tetrapropane-2,2',2",2"'-tetraol (modifier B) (c).

\section{2. Synthesis of Modified Unsaturated Polyester Resins}

To a three-necked $500 \mathrm{~mL}$ flask equipped with a mechanical stirrer, inlet to inert gas (nitrogen), thermometer, Liebig condenser and calibrated distillate collector, $76.1 \mathrm{~g}$
(0.5 mol) of phtalic anhydride, $49.0 \mathrm{~g}(0.5 \mathrm{~mol})$ of maleic anhydride, $41.0 \mathrm{~g}(0.43 \mathrm{~mol})$ of diethylene glycol, 42-44 $\mathrm{mL}(0.57-0.60 \mathrm{~mol})$ of propylene glycol (depending on the amount of amine-glycol modifier added), and the modifier itself up to $6.4 \mathrm{~g}$ ( $2.0 \mathrm{wt}$.- $\%$ with respect to the total mass of 
all substrates) were introduced. The flask was purged with nitrogen for $15 \mathrm{~min}$ before heating was switched on. Then $0.18 \mathrm{~mL}$ (ca. $12 \mathrm{mg}$ ) of $10 \%$ solution of hydroquinone in acetone was added and the content heated at $165-200{ }^{\circ} \mathrm{C}$ under nitrogen for 9-12 h, until the acid number of the mixture has dropped down to below $50 \mathrm{mg} \mathrm{KOH}$ per $\mathrm{g}$ of resin. ${ }^{22}$ The mixture was then cooled down to $90-100{ }^{\circ} \mathrm{C}$ and diluted with $125 \mathrm{~mL}$ of styrene stabilized with hydroquinone.

\section{2. 3. Curing of Unsaturated Polyester Resins}

By using normalized procedures, time of gelation at $25{ }^{\circ} \mathrm{C}$ (time until air bubble was arrested in the test tube filled with resin containing initiator $)^{23}$ and stability of resins at $70{ }^{\circ} \mathrm{C}$ (time until air bubble was arrested in the test tube filled with resin containing no initiator) ${ }^{24}$ were determined for all unsaturated polyester resins. The time of gelation was measured for the so-called amine-curing system, i.e. with benzoyl peroxide as initiator, for cobalt-curing system consisting of butanone peroxide initiator and cobalt(II) 2-ethylhexanoate accelerator. A series of curing experiments with cobalt curing system was performed with an addition of 0.3 wt.- $\%$ of benzyltriethylammonium chloride.

\section{3. Analytical Methods}

The addition reaction of amine to oxiranes was followed by determining the epoxy number of the reaction mixture using hydrochloric acid solution in dioxane. ${ }^{25}{ }^{1} \mathrm{H}$ NMR spectra of the products were recorded at $25^{\circ} \mathrm{C}$ in deuterated dimethyl sulfoxide (DMSO- $d_{6}$ ) with hexamethyldisiloxane internal standard on a Bruker AM 500 $\mathrm{MHz}$, Germany. IR spectra were recorded as $\mathrm{KBr}$ pellets on a Perkin-Elmer PARAGON 1000 FT spectrometer (Wellesley, MA, USA). Elemental analyses were determined on a Vario EL III C, H, N, S and O apparatus (Elementar, Germany).

The process of polycondensation leading to unsaturated polyester resins was followed by measuring the amount of water released from the system and, at the end of the reaction, by measuring the acid number (AN) of the reaction mixture. The reaction was ended when AN was smaller than ca. $50 \mathrm{mg} \mathrm{KOH}$ per g of resin. ${ }^{22}$ Hydroxyl numbers (HN) of alkyds used for preparing unsaturated polyester resins were also measured according to the standard procedures. ${ }^{26}$

\section{Results and Discussion}

\section{1. Synthesis of Modifiers A and B}

The amine-glycol modifiers for unsaturated polyester resins were obtained in a one step reaction between 1 mol of phenylene-1,2-diamine and 4 mol of ethylene oxide or $4 \mathrm{~mol}$ of propylene oxide. The reaction yielded alcohols with four hydroxyl groups containing tertiary amino groups with nitrogen atoms linked directly to the aromatic ring (scheme 1).

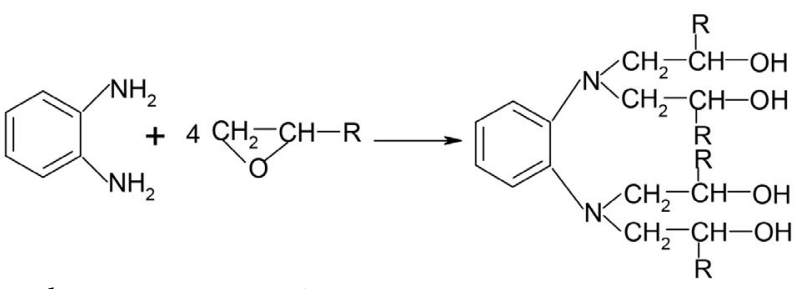

where: $\mathrm{R}=-\mathrm{H}$ or $-\mathrm{CH}_{3}$

Scheme 1. Obtaining modifiers for unsaturated polyester resins

The course of the reaction was confirmed by the vanishing IR absorption bands at $3386,3364,3283,3185 \mathrm{~cm}^{-1}$ due to the stretching vibrations and at 1458 (vibrations in plane), 1321, 1274, and $1248 \mathrm{~cm}^{-1}$ (vibrations out of plane) due to deformational vibrations of amino groups. Appearance of new broad bands was observed due to hydroxyl groups at 3306 and $3338 \mathrm{~cm}^{-1}$ (associated hydroxyl groups). Bands at 1067 and $1044 \mathrm{~cm}^{-1}$ (modifier A) and bands at 1072 and $1054 \mathrm{~cm}^{-1}$ (modifier B) corresponding to stretching vibrations of $\mathrm{C}-\mathrm{O}$ bonds in primary and secondary alcohols, as well as those at 1198 and $1133 \mathrm{~cm}^{-1}$ due to deformational vibrations of hydroxyl groups were also present (Fig. 1). Similarly, in ${ }^{1} \mathrm{H}$ NMR spectra (Fig. 2), the signal at $4.36 \mathrm{ppm}$ from amine protons disappeared and appeared instead a signal at $4.53 \mathrm{ppm}$ from hydroxyl protons in 2-hydroxyethyl groups (modifier A) or two signals at 4.47 and $4.52 \mathrm{ppm}$ from $\mathrm{OH}$ protons (for the normal product) and also two signals at 4.90 and $5.18 \mathrm{ppm}$ from $\mathrm{OH}$ protons (for the regioisomer, anomalous product) in 2-hydroxypropyl groups (modifier B). These four last signals are related to configuration at the chiral carbon atom in the each hydroxypropyl group. In the case of modifier A, a signal from methylene protons appeared at 3.19 and $3.40 \mathrm{ppm}$, whereas for modifier B three extra peaks from methyl protons could be seen in the spectra in two ranges: the first one at 0.95 and 0.96 ppm for methyl protons in normal product and the second one at 0.97 and $0.98 \mathrm{ppm}$ for methyl protons in anomalous product, beside methylene protons signal from 2.80 to $3.35 \mathrm{ppm}$, as well as from methine proton at $3.65 \mathrm{ppm}$. By comparing the signal intensities it was found that ca. $70 \%$ of the product of the reaction of phenylene-1,2-diamine with propylene oxide was the normal one, and the rest was the anomalous one. The reason is that proton in amino groups in ortho position may form a five-membered ring including $\mathrm{H}-\mathrm{N}$ hydrogen bond. The weakly linked proton engaged in the hydrogen bond can easily be linked to oxirane oxygen. The result is that a partial positive charge is formed on the most substituted oxirane carbon which can be attacked by the amine electron pair (Scheme 2). This may explain why so much of the anomalous product is formed. 


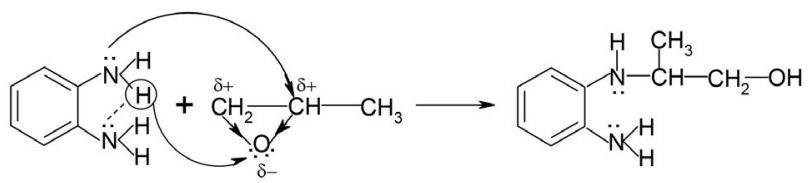

Scheme 2. The formation of the anomalous product.

The anomalous product of addition of propylene oxide to aromatic amine may contribute to the hindering of gelation, as explained later in the text.

The difference between resonance positions of signals from methylene and methine protons in modifier $B$ is a result of strongly electronegative character of the oxygen in hydroxyl group, which is stronger than that from the nitrogen at the aromatic ring. The signals from 6.85 to $7.10 \mathrm{ppm}$ and from 6.80 to $7.10 \mathrm{ppm}$ due to aromatic protons appear in spectra of modifier A and modifier B, respectively.

\section{2. Gelation Time for Modified Unsaturated Polyester Resins}

The products modifier A: benzene-1,2-diamine$N, N, N, N^{\prime}$-tetraethane-2,2'2",2"'-tetraol and modifier B: benzene-1,2-diamine- $N, N, N, N^{\prime}$-tetrapropane-2,2',2",2"'tetraol were built into the structure of an unsaturated polyester resins and their effects on gelation time and stability of the resin were observed. The reference resin was prepared by condensation of phthalic and maleic anhydride with propane-1,2-diol (propylene glycol) and 3-oxapentane-1,5-diol (diethylene glycol). ${ }^{27}$ This is a typical construction brand resin with 3-oxapentane-1,5-diol (diethylene glycol) acting as the stiffness-reducing monomer of polyester segments. Modification of the resins involved replacing a part of propylene glycol with one of the modifiers. The highest proportion of the modifier was established in the preliminary experiment not to exceed 1.5 mole $\%$. This was a sufficiently small quantity so that no gelation at polyesterification stage was observed in the presence of both four-functional modifiers. The unsaturated polyesters resins were synthesized by carrying condensation of the components at $165-200{ }^{\circ} \mathrm{C}$ under nitrogen until the acid number of the reaction mixture dropped down below $50 \mathrm{mg} \mathrm{KOH}$ per $\mathrm{g}$ of resin. ${ }^{28}$ As the amount of modifiers increased, the color of modified resins became more and more dark, from yellowish, and yellow at the concentration of modifiers $\mathrm{A}$ and $\mathrm{B}$ equal about 0.002 to

Table 5. Characteristic of UP Resins with Amine Modifiers Incorporated into Their Chemical Structure

\begin{tabular}{|c|c|c|c|c|c|c|c|c|}
\hline $\begin{array}{l}\text { Kind of } \\
\text { modifier }\end{array}$ & $\begin{array}{l}\text { Number } \\
\text { of resin }\end{array}$ & $\begin{array}{l}\text { Mole of amine } \\
\text { accelerating } \\
\text { groups } / \mathbf{k g} \\
\text { resin }\left(\mathbf{x 1 0}^{-3}\right)\end{array}$ & $\begin{array}{l}\text { Wt.-\% of } \\
\text { modifier }\end{array}$ & $\begin{array}{c}\mathrm{AN} \\
(\mathrm{mg} / \mathrm{KOH} / \mathrm{g})\end{array}$ & $\begin{array}{c}\mathrm{HN} \\
(\mathrm{mg} / \mathrm{KOH} / \mathrm{g})\end{array}$ & $\begin{array}{l}\text { Stability of } r \\
\text { Without } \\
\text { ammonium } \\
\text { salt (h) }\end{array}$ & $\begin{array}{c}\text { ins at } 70^{\circ} \mathrm{C} \\
\text { With } \\
\text { ammonium } \\
\text { salt (h) }\end{array}$ & Color \\
\hline 1 & 2 & 3 & 4 & 5 & 6 & 7 & 8 & 9 \\
\hline None & 1 & 0.000 & 0.000 & 45.23 & 55.18 & 824 & 2658 & Colorless \\
\hline \multirow{12}{*}{ Modi-fier A } & 2 & 0.023 & 0.002 & 43.66 & 54.22 & 156 & 531 & Yellowish \\
\hline & 3 & 0.057 & 0.005 & 48.98 & 56.38 & 130 & 471 & Yellowish \\
\hline & 4 & 0.113 & 0.010 & 40.24 & 48.98 & 114 & 435 & Yellow \\
\hline & 5 & 0.226 & 0.020 & 47.63 & 56.70 & 102 & 372 & Dark yellow \\
\hline & 6 & 0.565 & 0.050 & 48.12 & 58.27 & 45 & 165 & Dark yellow \\
\hline & 7 & 1.130 & 0.100 & 40.72 & 47.37 & 21 & 120 & Light brown \\
\hline & 8 & 2.825 & 0.250 & 46.53 & 55.97 & 12 & 96 & Light brown \\
\hline & 9 & 5.651 & 0.500 & 40.67 & 48.13 & 9 & 75 & Brown \\
\hline & 10 & 8.477 & 0.750 & 45.76 & 55.96 & 9 & 72 & Brown \\
\hline & 11 & 11.302 & 1.000 & 44.83 & 53.28 & 9 & 72 & Dark brown \\
\hline & 12 & 14.128 & 1.250 & 47.46 & 56.67 & 9 & 72 & Dark brown \\
\hline & 13 & 16.954 & 1.500 & 45.47 & 55.09 & 9 & 72 & Brown black \\
\hline \multirow{12}{*}{ Modi-fier B } & 14 & 0.019 & 0.002 & 43.87 & 52.21 & 555 & 1044 & Yellowish \\
\hline & 15 & 0.047 & 0.005 & 39.93 & 48.65 & 360 & 972 & Yellowish \\
\hline & 16 & 0.094 & 0.010 & 43.36 & 54.42 & 234 & 891 & Yellow \\
\hline & 17 & 0.189 & 0.020 & 47.02 & 57.02 & 171 & 765 & Dark yellow \\
\hline & 18 & 0.472 & 0.050 & 42.08 & 51.05 & 111 & 612 & Dark yellow \\
\hline & 19 & 0.944 & 0.100 & 45.01 & 55.42 & 51 & 309 & Light brown \\
\hline & 20 & 2.35 & 0.250 & 45.84 & 55.76 & 69 & 216 & Light brown \\
\hline & 21 & 4.720 & 0.500 & 49.69 & 59.31 & 90 & 285 & Brown \\
\hline & 22 & 7.080 & 0.750 & 49.29 & 59.23 & 105 & 360 & Brown \\
\hline & 23 & 9.440 & 1.000 & 46.03 & 55.36 & 126 & 396 & Dark brown \\
\hline & 24 & 11.800 & 1.250 & 44.58 & 53.26 & 150 & 399 & Dark brown \\
\hline & 25 & 14.160 & 1.500 & 45.90 & 55.28 & 162 & 399 & Brown black \\
\hline
\end{tabular}


0.010 wt.- $\%$ to dark brown and brown black at the concentration from 1.00 to $1.50 \mathrm{wt} .-\%$.

By using normalized procedures, time of gelation at $25{ }^{\circ} \mathrm{C}$ (time until air bubble was arrested in the test tube filled with resin containing initiator $)^{23}$ and stability of resins at $70{ }^{\circ} \mathrm{C}$ (time until air bubble was arrested in the test tube filled with resin containing no initiator $)^{24}$ were determined for all unsaturated polyester resins. The standard initiator for the cobalt-curing of unsaturated polyester resins was used. Namely, the system consisted of cobalt(II) 2-ethylhexanoate as accelerator and butanone peroxide initiator dispersed in dibutyl 1,2-phthalate (Luperox K-1). The attempt of using benzoyl peroxide dispersed in dibutyl 1,2-phthalate (Interox BP-50-P1) was unsuccessful for too long gelation times. The times of gelation were therefore measured for cobalt-curing system consisting of butanone peroxide (Luperox K-1) initiator and cobalt(II) 2-ethylhexanoate accelerator. A series of curing experiments with cobalt curing system was performed with an addition of 0.3 wt.- $\%$ of benzyltriethylammonium chloride. Even in the absence of initiator the resin gelled when heated to $70{ }^{\circ} \mathrm{C}$. The results of stability tests are presented in Table 5 .

The shelf stability of the modified unsaturated polyesters reduced with the increasing amount of modifiers $\mathrm{A}$ or B added to reaction of polycondensation. This was result of the presence of tertiary amino groups linked to the aromatic ring built into polyester chain, the groups that are known for their significant reduction of threshold energy of double bond decomposition or cleavage. Generally, the modifiers containing 2-hydroxylethyl substituents at the nitrogen atom (such as modifier $\mathrm{A}$ ) are much more active and show a much shorter gel times than those with 2-hydroxypropyl substituents (modifier B). This can be seen especially for the modified resins increased amount modifier B (from 0.50 to 1.50 wt.-\%). For the resins with a builtin modifier $A$ all the gelation times are shorter than the unmodified resin, where for the four series of experiments were made with cobalt solution content of $0.10,0.15,0.25$, or $0.50 \mathrm{~mL}$ per $25 \mathrm{~g}$ of resin. For unmodified resin the respective gelation times were $92,72,50.5$, or $42.5 \mathrm{~min}$ for the normative amount of initiator $(2 \mathrm{wt} .-\%) .{ }^{24}$ However, for unsaturated polyesters with built-in modifier B two ranges of gelation times were observed. The first of the ranges with gelation times shorter than those of unmodified resins, was observed with 0.002 to about 0.25 wt.- $\%$ of modifier B built into the resin structure. Then, the modifier acted as a pre-accelerator. The second range of gelation times much longer than those for unmodified resins contained 0.25 to 1.50 wt.- $\%$ of modifier B, in this case acting as an inhibitor of gelation times.

Gelation times for the modified resins are shown in Figures 3 and 4. In Figures 5 and 6 the dependence of gelation time is plotted against the amount of cobalt accelerator for resins prepared with different amounts of modifiers $\mathrm{A}$ and $\mathrm{B}$. The reactivity and stability measurements were carried out by changing the content of modifiers built into the structure of unsaturated polyester resins (Figs. 3 and 4) and the amount of cobalt accelerator (Figs. 5 and 6).

To summarize, incorporation of modifier A into the structure of resin in the whole range of concentration from 0.002 to 1.50 wt.- $\%$ results in faster gelation of resin com-
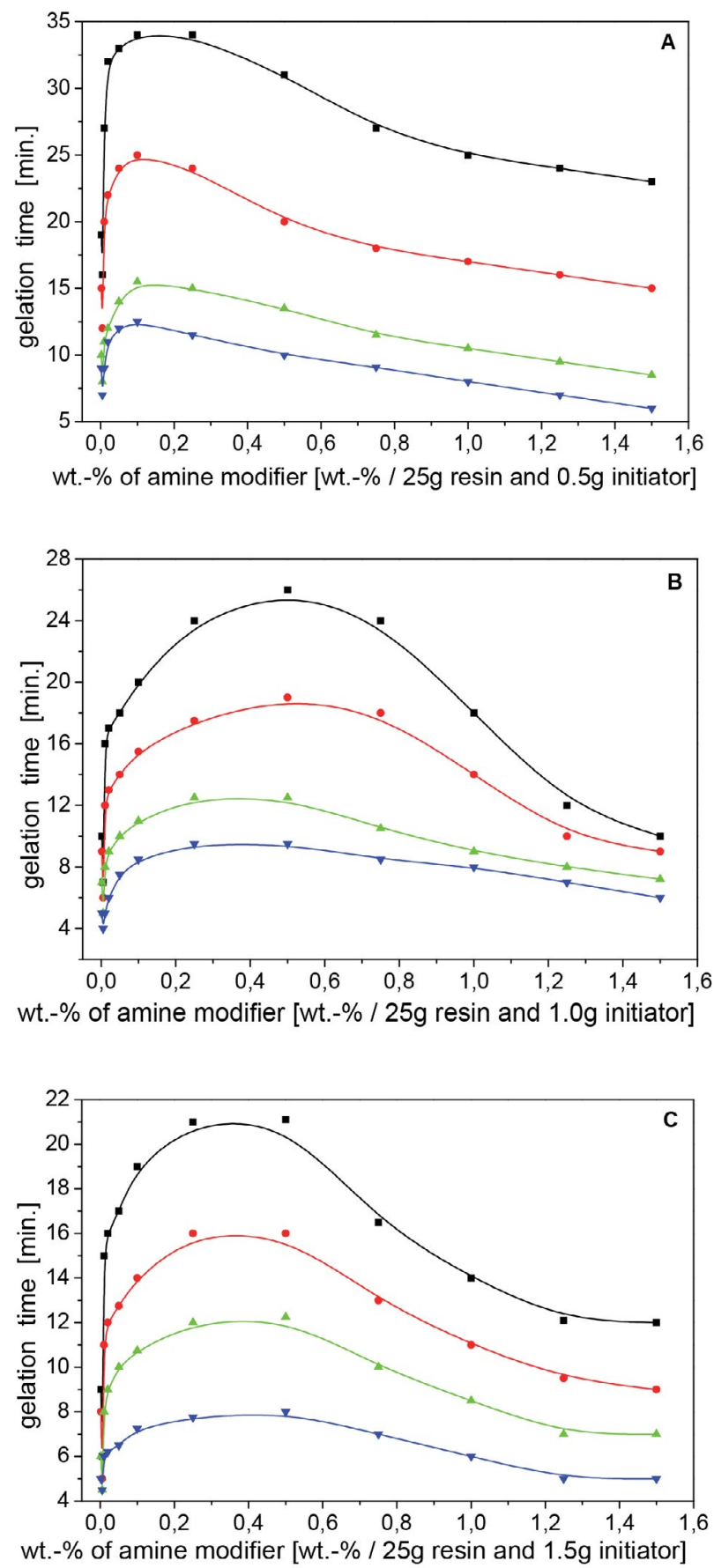

Figure 3. Gelation times of unsaturated polyesters resins with various amount of chemically incorporated modifier A and cobalt accelerator. To $25 \mathrm{~g}$ of resin, $0.5 \mathrm{~g}$ (plot A), $1.0 \mathrm{~g}$ (plot B), and $1.5 \mathrm{~g}$ (plot $\mathrm{C}$ ) of butanone peroxide initiator was added; the amounts of cobalt accelerator: $(\bullet), 0.10 \mathrm{~mL} ;(\bullet), 0.15 \mathrm{~mL} ;(\Delta), 0.25 \mathrm{~mL} ;(\boldsymbol{\nabla}), 0.50$ $\mathrm{mL}$. 


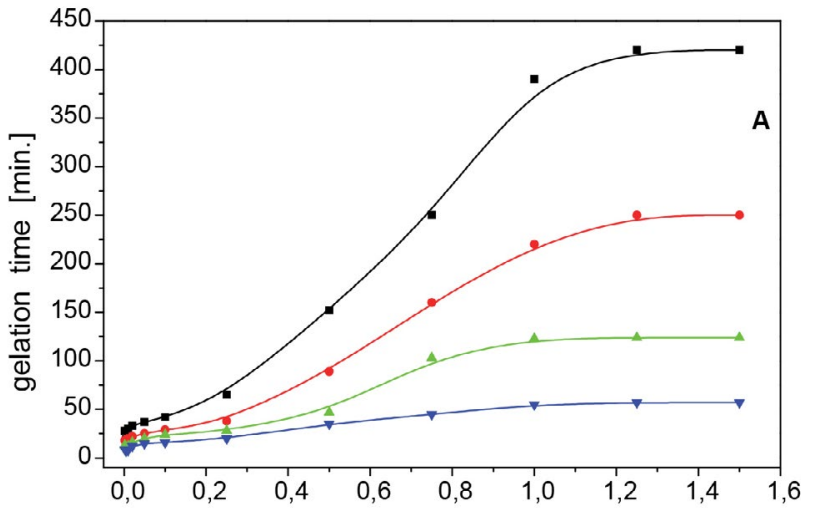

wt.- $\%$ of amine modifier [wt.- $\% / 25 \mathrm{~g}$ resin and $0.5 \mathrm{~g}$ initiator]

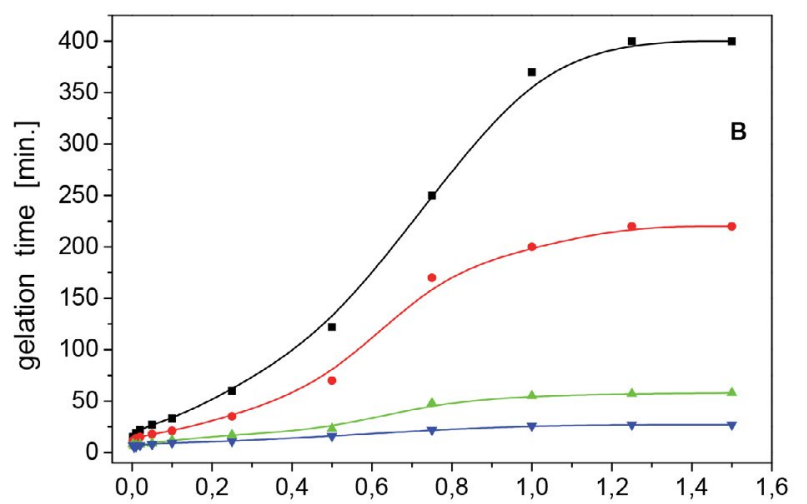

wt.- $\%$ of amine modifier [wt.- $\% / 25 \mathrm{~g}$ resin and $1.0 \mathrm{~g}$ initiator]

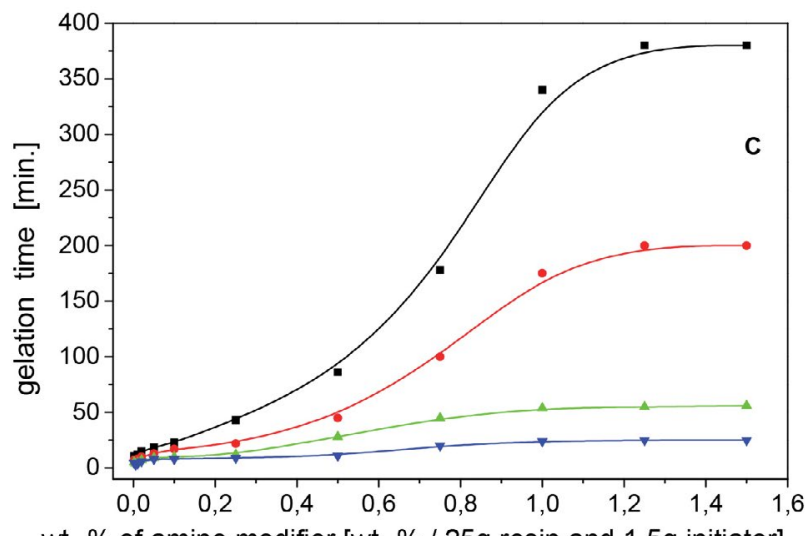

wt.-\% of amine modifier [wt.- $\% / 25 \mathrm{~g}$ resin and $1.5 \mathrm{~g}$ initiator]

Figure 4. Gelation times of unsaturated polyesters resins with various amount of chemically incorporated modifier $B$ and cobalt accelerator. To $25 \mathrm{~g}$ of resin, $0.5 \mathrm{~g}$ (plot $\mathrm{A}$ ), $1.0 \mathrm{~g}$ (plot B), and $1.5 \mathrm{~g}$ (plot C) of butanone peroxide initiator was added; the amounts of cobalt accelerator: $(\bullet), 0.10 \mathrm{~mL} ;(\bullet), 0.15 \mathrm{~mL} ;(\Delta), 0.25 \mathrm{~mL} ;(\nabla), 0.50 \mathrm{~mL}$.

pared to the resin without modifier. In the case of modifier $\mathrm{B}$, however, the fundamental effect on gelation time had the addition of cobalt accelerator (1.0\% solution of cobalt(II) 2-ethylhexanoate in styrene). When used in the amount of 0.002 to ca. 0.25 wt.- $\%$, modifier B serves as an accelerator. The effect is extended to up to ca. $0.50 \mathrm{wt} .-\%$, when more cobalt accelerator is present in the system $(0.50 \mathrm{~mL}$ per $25 \mathrm{~g}$ of resin at the normative initiator con-
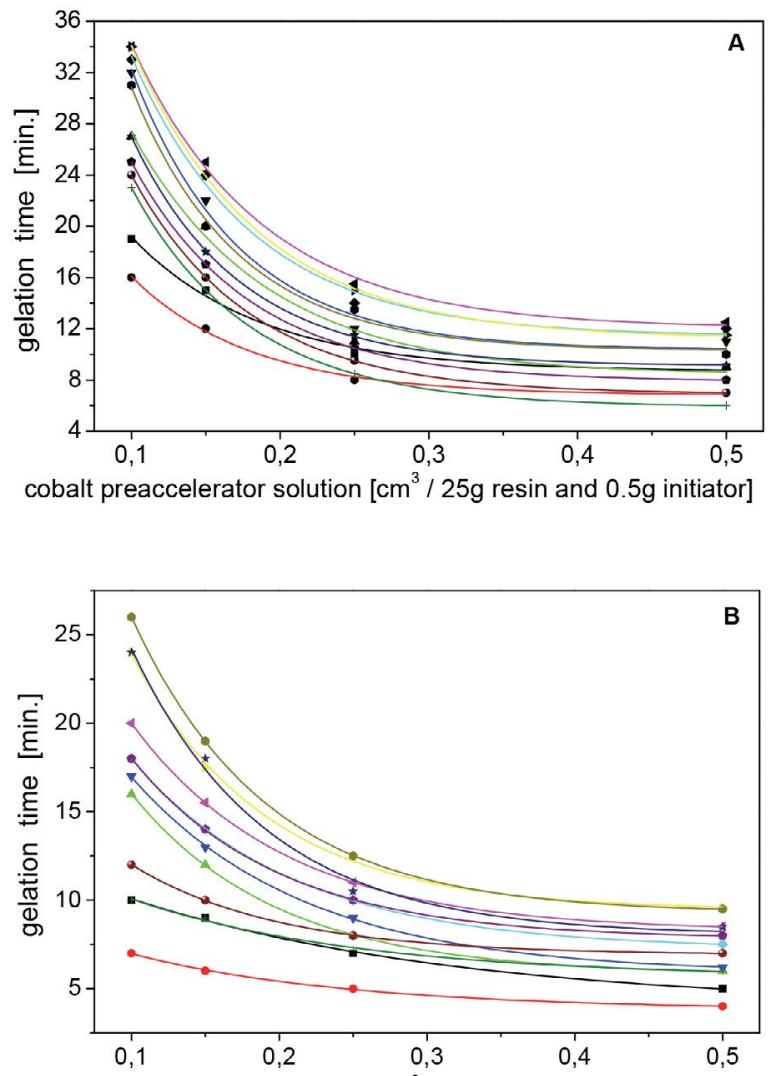

cobalt preaccelerator solution $\left[\mathrm{cm}^{3} / 25 \mathrm{~g}\right.$ resin and $1.0 \mathrm{~g}$ initiator]

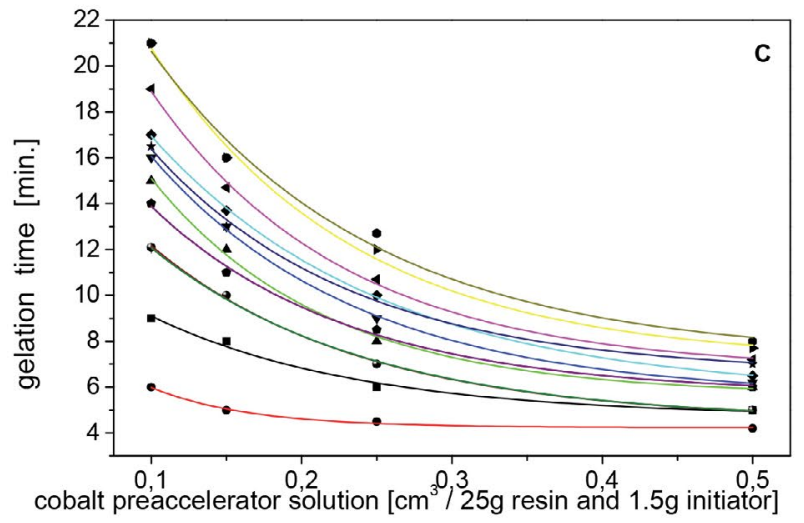

Figure 5. Gelation times of unsaturated polyesters resins with various amount of cobalt accelerator solution and various amounts of chemically incorporated modifier A. To $25 \mathrm{~g}$ of resin, $0.5 \mathrm{~g}$ (plot A), $1.0 \mathrm{~g}$ (plot $\mathrm{B}$ ), and $1.5 \mathrm{~g}$ (plot $\mathrm{C}$ ) of butanone peroxide initiator was added; the amounts of chemically incorporated modifier A: $(\mathbf{\bullet})$, 0.002 wt.-\%; $(\bullet), 0.005$ wt.-\%; (A), 0.010 wt.-\%; ( $\nabla), 0.020$ wt.-\%; (॰), 0.050 wt.-\%; (+), 0.100 wt.-\%; ( ), 0.250 wt.-\%; (*), 0.500 wt.$\%$; (*), 0.750 wt.-\%; (•), 1.000 wt.-\%; (०), 1.250 wt.-\%, (+) 1.500 wt.-\%.

tent) with an extra amount of initiator, higher than that recommended ( 1.0 or $1.5 \mathrm{~g}$ per $25 \mathrm{~g}$ of resin) and $0.5 \mathrm{~mL}$ of cobalt accelerator leads to faster gelation of modified resins. This system of curing composition yields shorter gelation times in the whole concentration range of modifiers studied. 


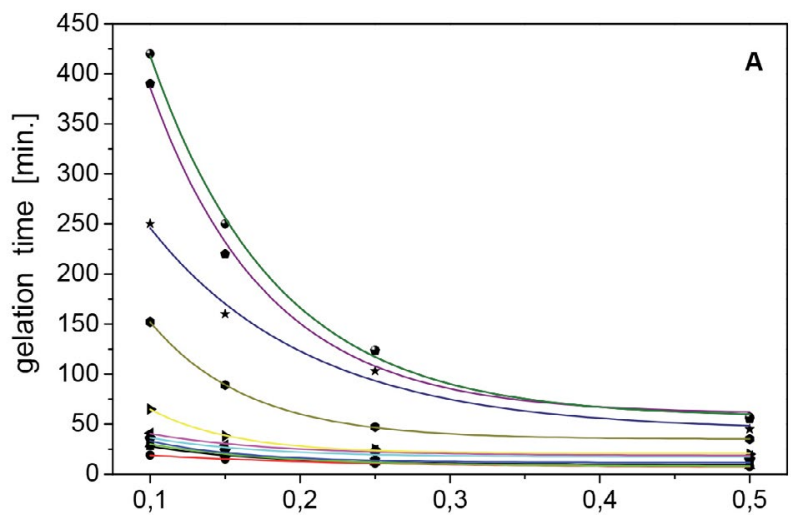

cobalt preaccelerator solution $\left[\mathrm{cm}^{3} / 25 \mathrm{~g}\right.$ resin and $0.5 \mathrm{~g}$ initiator]

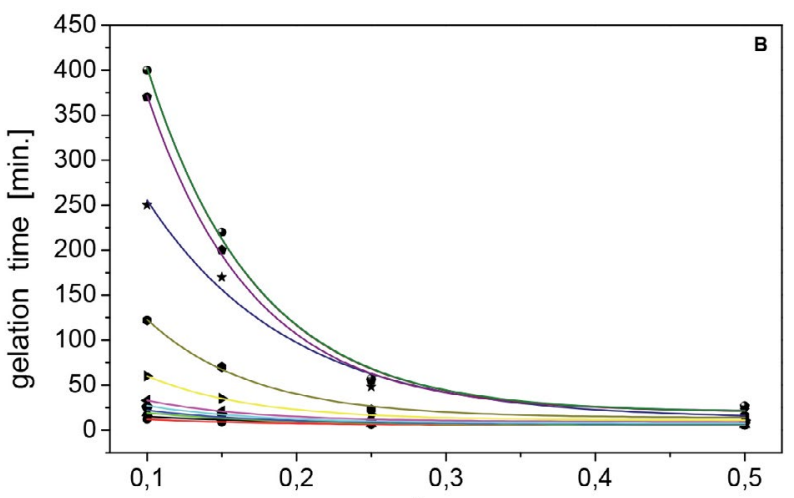

cobalt preaccelerator solution $\left[\mathrm{cm}^{3} / 25 \mathrm{~g}\right.$ resin and $1.0 \mathrm{~g}$ initiator]

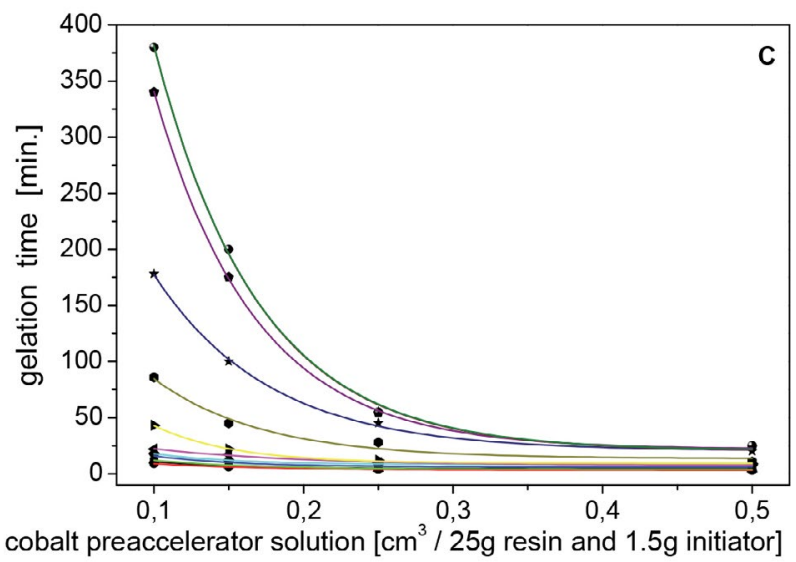

Figure 6. Gelation times of unsaturated polyesters resins with various amount of cobalt accelerator solution and various amounts of chemically incorporated modifier B. To $25 \mathrm{~g}$ of resin, $0.5 \mathrm{~g}$ (plot A), $1.0 \mathrm{~g}$ (plot B), and $1.5 \mathrm{~g}$ (plot C) of butanone peroxide initiator was added; the amounts of chemi-

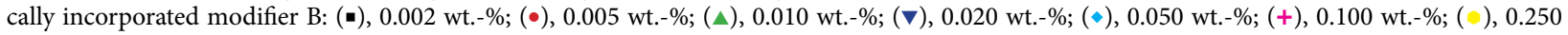
wt.-\%; (*), 0.500 wt.-\%; ( $), 0.750$ wt.-\%; (•), 1.000 wt.-\%; (०), 1.250 wt.-\%, (+) 1.500 wt.- $\%$.
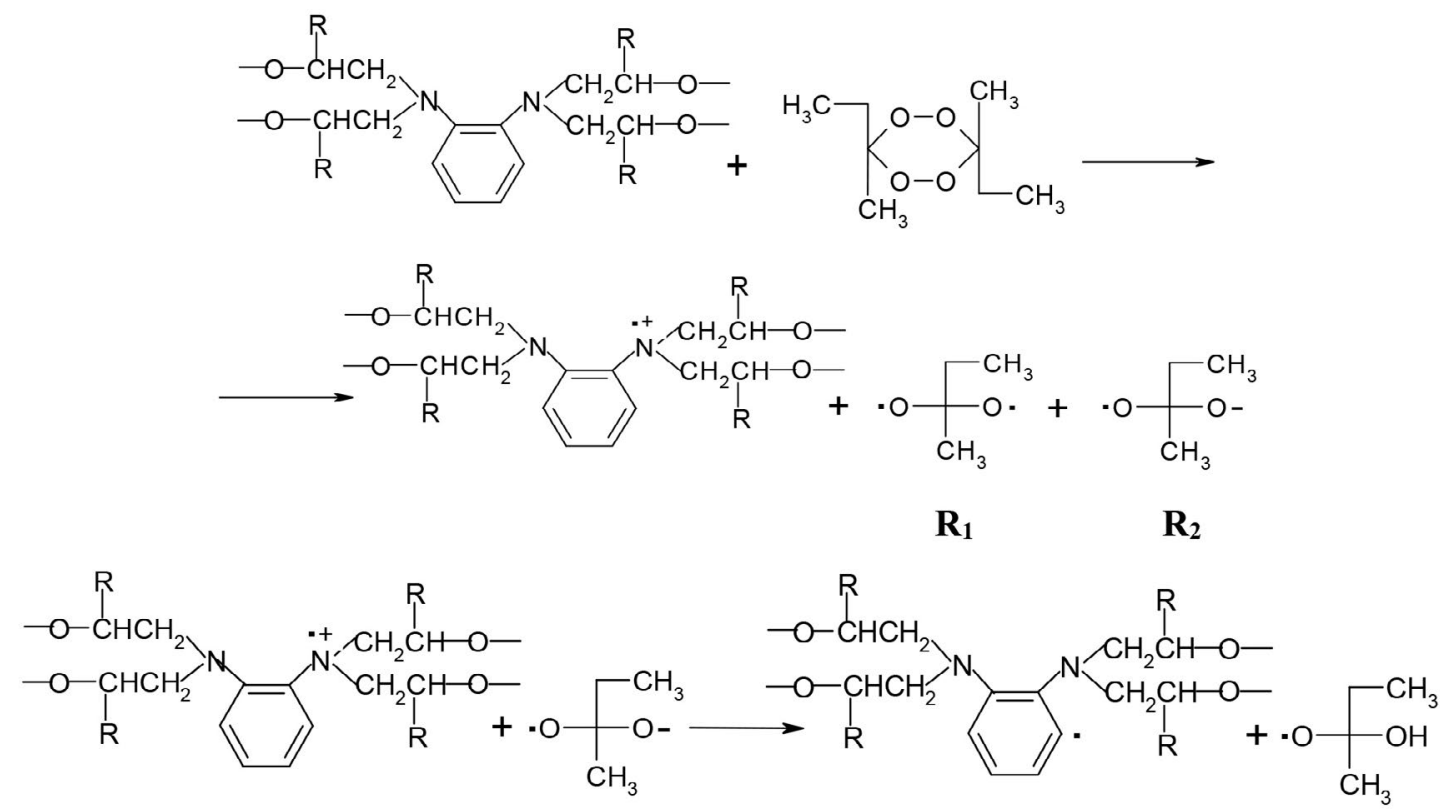

where: $\mathrm{R}=-\mathrm{H}$ or $-\mathrm{CH}_{3}$

$\mathbf{R}_{3}$

Scheme 3. The reaction between the built-in amine pre-accelerator in the polyester structure and the peroxide initiator 
Based on the analysis of the results one can conclude that incorporation of modifier A into the resin structure in the whole range of concentrations, from 0.002 to $1.50 \mathrm{wt}$.$\%$., results in faster gelation of resin compared to that without modifier. However, for modifier B a fundamental effect on the change in gelation time is addition of cobalt accelerator (1.0\% solution of cobalt(II) 2-ethylhexanoate in styrene). An increase of gelation time for resins with modifier B can be observed, especially for the system which contains a large amount of cobalt accelerator $(0.50 \mathrm{~mL}$ per 25 $\mathrm{g}$ of modified resins) and for the over-normative amount of initiator (4 and 6 wt.- $\%) .^{23}$

The reason might be the high concentration of amine. The modifier acts as a scavenger of radicals formed from initiator. As follows from the literature data ${ }^{1,28,29}$ amines may act not just as promoters of initiator decomposition, but also as stabilizers preventing radicals formed naturally to propagate into a chain reaction in organic systems. Also the amines built into resin may react with macroradicals thus reducing the rate of polymerization. The process may proceed according to the Scheme 3.

As a result of these reactions diradicals $\left(\mathbf{R}_{\mathbf{1}}\right)$ and anion radicals $\left(\mathbf{R}_{\mathbf{2}}\right)$ are formed from peroxide molecule and also mesomerically stabilized radicals are formed from amino-modifier $\left(\mathbf{R}_{\mathbf{3}}\right)$ built-into the polyester chain. These radicals initiate the process of polymerization of the polyester chain double bonds or those of styrene.
By comparing actions of pre-accelerators of similar structures prepared from phenylene-1,4-amine and phenylene-1,3-amine, as described in the literature, ${ }^{20,21}$ one should note that in the case of hydroxyalkyl derivatives of phenylene-1,2-amine, although in the latter there exist four active sites capable of initiating radical polymerization, but not all are equally accessible.

From the point of view of stereochemistry, accessible are only two sites denoted as 'a', while the activity of radicals in position ' $\mathbf{b}$ ' may be considerably limited by the presence of large and bulky alkyl substituents (this is particularly true for resins containing phenylene-1,3-diamine pre-accelerator).

An extra steric hindrance is exerted by the presence of a methyl group in hydroxyalkyl substituent of modifier B. This seems to be the reason why unsaturated polyester resins modified with benzene-1,2-diamine- $N, N, N, N^{\prime}$-tetrapropane 2,2',2",2"'-tetraol (modifier B) exhibit relatively long gelation times, particularly when a small amount of cobalt modifier is applied. The resins modified with benzene-1,2-diamine- $N, N, N, N$ 'tetraethane-2,2',2",2"'-tetraol (modifier A) do gel faster.

The absence of bulky methyl group in 2-hydoxyethyl substituent of modifier A facilitates access to the reactive sites such as ' $\mathbf{a}$ ' as well as ' $\mathbf{b}$ '. The use of higher concentration of cobalt salt significantly accelerates gelation process, as a greater number of aromatic active radicals are used. At

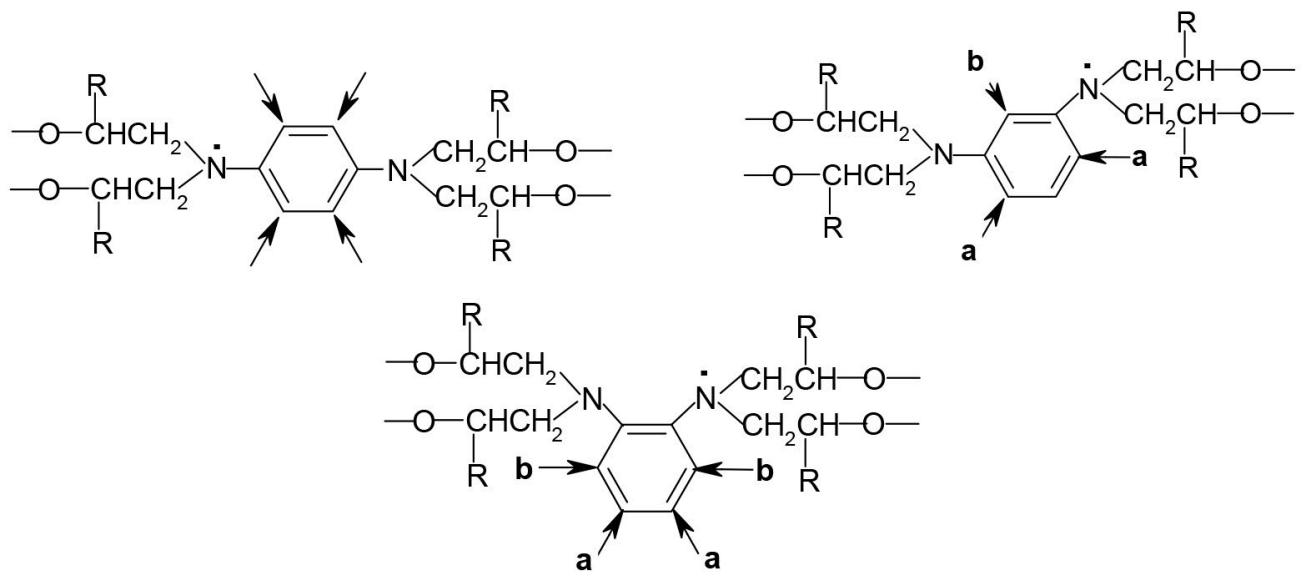

Scheme 4. Active sites in amine pre-accelerators.

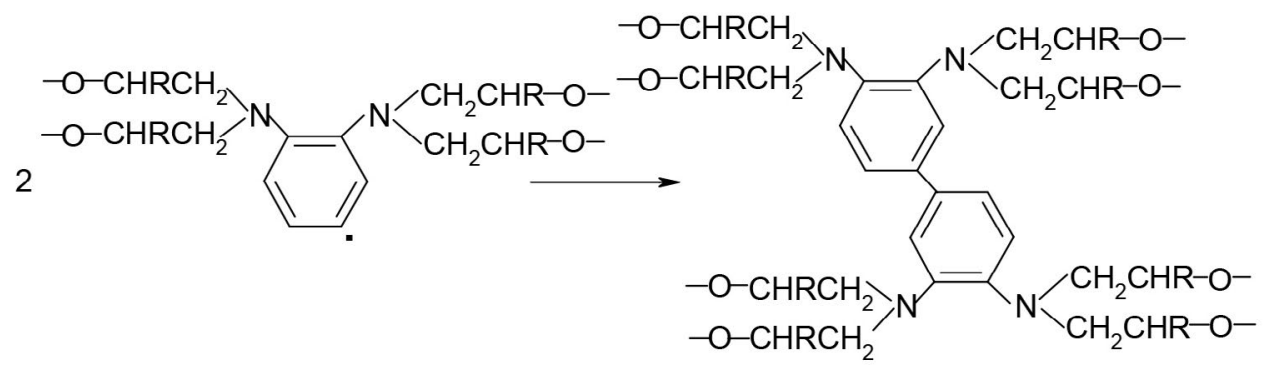

Scheme 5. Deactivation of radicals during gelation 
the lowest cobalt concentration, on the other hand, $(0.10$ or $0.25 \mathrm{~mL}$ per $25 \mathrm{~g}$ of resin) the concentration of aromatic radicals is so high that an inhibiting effect of gelation process is observed according to the reaction presented in Scheme 5.

The gelation times were measured for four different amounts of cobalt accelerator added. For the resin not containing a built-in modifier, gelation times were: 92, 72, 50.5 , and $42.5 \mathrm{~min}$. for systems with the normative amount of initiator (i.e. $0.5 \mathrm{~g}$ of initiator per $25 \mathrm{~g}$ of resin) and 0.10 ; $0.15 ; 0.25$ and $0.50 \mathrm{~mL}$ of cobalt accelerator, respectively. ${ }^{29}$ The graphical dependence of gelation time $v s$. percentage of built-in amine modifier is presented in Figs. 3 and 4 .

It follows from the plots presented that the shortest gelation times are observed for unsaturated polyester resins with 0.002 to 1.50 wt. $\%$ of modifier A with the minimum at 0.005 wt.- $\%$. With doubled amount of initiator, relative to the normative one ${ }^{23}$ i.e. $4 \mathrm{wt} .-\%$ gelation time becomes reduced by ca. $50 \%$ at the constant concentration of $\mathrm{Co}$ (II) ( $c f$. curves A and B in Fig. 3).

With increasing concentration of cobalt accelerator, however, the reduction of gelation times becomes less and less pronounced, so that for resins cured with the normative $(0.5 \mathrm{~g})$ (i.e. 2 wt.-\%) and over-normative $(1.0 \mathrm{~g})$ (i.e. 4 wt.-\%) amounts of peroxide initiator the plots become more and more flat. The differences between the shortest and longest gelation time vanish with increasing amount of cobalt(II) concentration. The most reactive are resins with built-in $0.005 \%$ of modifier A.

Further increase of initiator content to $1.5 \mathrm{~g}$ (6\% per resin) did not change gelation time so significantly and, hence, gelation time got shortened by only about $10 \%$ (in relation to the previous system, i.e. with $1.0 \mathrm{~g}$ of initiator per $25 \mathrm{~g}$ of resin). To summarize, one can state that doubling the content of initiator from 2 to $4 \%$ results in substantial reduction of gelation time, by as much as $50 \%$ ( $c f$. curves A and B in Fig. 3), while further increase of initiator content, up to $6 \%$, only slightly reduces gelation time (cf. curves $\mathrm{B}$ and $\mathrm{C}$ in Fig. 3).

The behavior of the resins containing modifier $\mathrm{B}$ has been found to be completely different. Gelation times shorter than those for unmodified resin are obtained with 0.002 to ca. 0.25 wt.- $\%$ of modifier B built into resin structure with minimum gelation time again corresponding to the content of 0.005 wt.-\%, similarly as for modifier A. Above 0.25 wt.- $\%$ of modifier B gelation times become much longer than for unmodified resin. Hence, in the range of content from 0.25 to 1.5 wt.- $\%$ modifier B acts as an inhibitor of polymerization.

The presence of $30 \%$ of anomalous product is probably responsible for the inhibiting effect observed, leading to the increase of gelation time. This could be explained by the following Scheme 6.

The radical formed on nitrogen atom in the reaction between initiator and modifier may form double bond with neighboring carbon atom by removing hydrogen radical (reaction a). Hydrogen radical then breaks the double bond in unsaturated resin or in styrene thus initiating chain reaction (reaction $b$ ). The products formed in reactions $a$ and $b$ produce primary or secondary radicals stabilized mesomerically, the reactivity of which (particularly of primary ones) is much higher than that of those

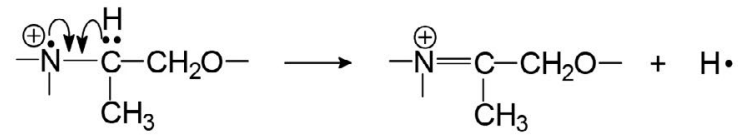
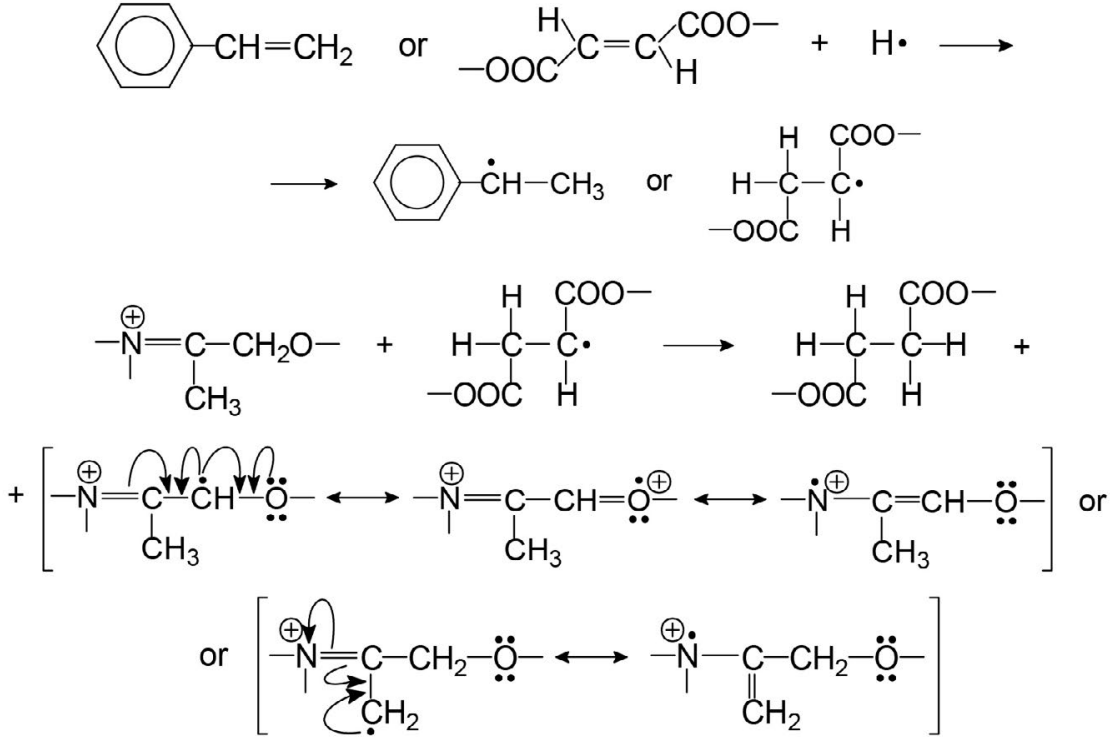

Scheme 6. A reaction cycle explaining the elongation of gelation time. 
formed at aromatic ring. As a result, radicals rapidly combine and polymerization process stops without utilizing double bonds of the resin (reaction b). This seems to be the reason why in the plot of gelation time $v s$. concentration of built-in modifier one observes rapid increase of gelation time.

By applying a higher than normative amount of initiator (i.e. $4 \%$ ) gelation time of resins containing modifier can be reduced by ca. $40 \%$, while still using the same amount of cobalt ( $c$ f. curves A and B in Fig. 4). ${ }^{23}$ Gradual increase of cobalt accelerator up to $0.5 \mathrm{~mL}$ per $25 \mathrm{~g}$ or resin respond with a similar reduction of gelation times. This effect becomes weaker and weaker as the amount of cobalt increases. Fivefold increase of $\mathrm{Co}^{2+}$ content results in three- to six-fold reduction of gelation time at the normative content of initiator. In the case of modifier B, the effect of extra initiator, however, is not as regular as in the case of modifier A. With $4 \%$ of initiator, the gelation times change irregularly and depend to a large extent on the amount of cobalt accelerator used. In general, a two-fold increase of initiator content reduced gelation time by 20 to $40 \%$ (cf. curves A and B in Fig. 4). Further increase of initiator content to $6 \%$ brings about 5 to $10 \%$ reduction of gelation time (cf. curves B and C in Fig. 4).

Reduced shelf stability of the resins as measured according to the appropriate standard procedure ${ }^{24}$ ( $c f$. Table 5 , column 7 ), is a serious disadvantage of the modifiers studied. The presence of tertiary amine built into unsaturated resins reduce not only the gelation time, but also reduce their long-time stability and hence the possibility of storage. This applies particularly to the resins containing 0.05 to $1.50 \%$ of modifier A for which the shelf stability were 45 to 9 hours (the time to gelation upon heating the resin without initiator at $70{ }^{\circ} \mathrm{C}$ ). The resins containing less modifier A, namely 0.002 to 0.02 wt. $\%$, the stability was in the range 156 to 102 hours ( $c f$. Table 5, column 7). Graph- ically, the relationship between shelf stability of the modified resins and the amount of modifier A resembles a hyperbola. In the case of modifier $B$ the shelf stability time was slightly longer and it was in the range 555 to 51 hours. In this case, the graphical form of the relationship resembles a parabola with minimum at 0.10 wt.- $\%$ of modifier B (cf. Table 5, column 7).

The stability of unsaturated polyester resin can be improved by using quaternary ammo-nium salt stabilizers. ${ }^{1,30}$ For the resins containing 0.3 wt.- $\%$ benzyltrimethylammonium chloride, the stability at $70{ }^{\circ} \mathrm{C}$ (Table 5 , columns 7 and 8) improved but to the extent again depending on the amount and kind of amine modifier built into resin.

Generally, the presence of an ammonium salt improved the stability of resins. Its effect was more pronounced for resins containing modifier $\mathrm{A}$, than for resins with modifier B. The stability increased 3.5 to 8 times and 2 to 6 times, respectively. The best stability values were recorded for 0.25 to 1.5 wt.- $\%$ content of modifier A and 0.10 wt.- $\%$ of modifier B. The latter coincide with the minimum of stability change caused by the presence of modifier B.

Gelation times were also measured for the resins stabilized with benzyltrimethylammonium chloride and initiated with a curing system consisting of $0.25 \mathrm{~mL}$ of cobalt accelerator and $0.5 \mathrm{~g}$ of peroxide per $25 \mathrm{~g}$ of resin. The results are shown in Table 6. For resins containing modifier A, gelation times increased by ca. 2.5 to 10 times as compared to analogous resins not containing quaternary ammonium stabilizer. For the resins containing modifier B, the respective increase of gelation time was ca. 2.5 in the whole range of the content of modifier B ( $c f$. columns 2 and 3 as well as column 4 and 5). The character of stability dependence on the amount of amine built into resin did not change in the presence of quaternary ammonium salt.

To summarize the results, for unsaturated polyester resins containing built-in modifier $\mathrm{A}$, much narrower

Table 6. Comparison of Gelation Times for UP Resins with Modifiers A and B Containing or Not the Benzyltriethylammonium Chloride Stabilizer

\begin{tabular}{|c|c|c|c|c|}
\hline \multirow{3}{*}{$\begin{array}{l}\text { Wt.-\% of } \\
\text { modifier }\end{array}$} & \multicolumn{4}{|c|}{ Gelation time (min) } \\
\hline & \multicolumn{2}{|c|}{ Modifier A } & \multicolumn{2}{|c|}{ Modifier B } \\
\hline & $\begin{array}{c}\text { Without ammonium } \\
\text { salt (min) }\end{array}$ & $\begin{array}{l}\text { With ammonium } \\
\text { salt (min) }\end{array}$ & $\begin{array}{l}\text { Without ammonium } \\
\text { salt (min) }\end{array}$ & $\begin{array}{l}\text { With ammonium } \\
\text { salt }(\mathrm{min})\end{array}$ \\
\hline 1 & 2 & 3 & 4 & 5 \\
\hline 0.002 & 10.0 & 95.0 & 13.0 & 30.0 \\
\hline 0.005 & 8.0 & 99.0 & 11.0 & 28.0 \\
\hline 0.010 & 11.0 & 101.0 & 12.0 & 32.0 \\
\hline 0.020 & 12.0 & 94.0 & 13.0 & 38.0 \\
\hline 0.050 & 14.0 & 85.0 & 22.0 & 42.0 \\
\hline 0.100 & 15.5 & 56.0 & 24.0 & 46.0 \\
\hline 0.250 & 15.0 & 36.0 & 25.0 & 58.0 \\
\hline 0.500 & 13.5 & 30.0 & 47.0 & 110.0 \\
\hline 0.750 & 11.5 & 25.0 & 103.0 & 233.0 \\
\hline 1.000 & 10.5 & 23.0 & 123.0 & 360.0 \\
\hline 1.250 & 9.5 & 22.0 & 124.0 & 420.0 \\
\hline 1.500 & 8.5 & 22.0 & 124.0 & 420.0 \\
\hline
\end{tabular}


range of gelation times is observed, as compared with those containing modifier B. The gelation times for the former changed from 7 to 34 minutes for the normative content of initiator (2.0 wt.-\%) and depended on the amount of cobalt(II) accelerator $(0.10-0.50 \mathrm{~mL}$ per $25 \mathrm{~g}$ resin). In the case of modifier $\mathrm{B}$, the respective gelation times were much longer for the same curing conditions and amounted from 7.5 to 420 minutes. The use of an over-normative amount of initiator (4.0 or $6.0 \mathrm{wt.} \%$ ) reduced gelation times, as expected.

Three parameters were found to have a major effect on the rate of gelation of modified unsaturated polyester resins. These are the amount of built-in modifier, the amount of initiator used for curing and the concentration of cobalt accelerator. Each of them influences the time gelation in its specific way. The amount of initiator modifies gelation time only when used in the amount 2 to 4 wt.- $\%$. At the higher amount of 6 wt.- $\%$ of butanone peroxide, the reactivity of the resin expressed in terms of gelation time does not increase significantly anymore. Somewhat less important is the amount of cobalt accelerator.

Table 6 summarizes gelation times of the compositions containing ammonium salt stabilizer with $2.0 \mathrm{wt} .-\%$ of initiator and $0.25 \mathrm{~mL}$ of cobalt accelerator per $25 \mathrm{~g}$ of resin. As compared to unstabilized ones the gelation times are from about eight to ten times longer for the resin containing from 0.002 to 0.02 wt. $\%$ as a modifier A or between 2 and 3 times longer for resins containing from 0.05 to $1.50 \mathrm{wt} .-\%$. The gelation times are from two to three times longer for the whole range of concentrations of modifier B (0.002-1.50 wt.-\%) used.

\section{Conclusions}

1. Tertiary amines with aromatic ring were obtained by reacting phenylene-1,2-diamine with ethylene oxide (A) and propylene oxide (B) and used as modifiers for unsaturated polyester resins.

2. The modifier A introduced into resins structure at the stage of polycondensation very strongly reduced gelation time of the resulting unsaturated polyester resin in the cobalt curing system.

3. The modifier B also reduced gelation time in the cobalt curing system, but to a much smaller extent.

4. The gelation time reduction was observed in cobalt curing system in the presence of at least $0.005 \mathrm{wt} .-\%$ of the both modifiers. For resins modified with from about 0.25 to 1.50 wt.- $\%$ of modifier B an increase of gelation time was observed as compared to that for unmodified resins. The most promising results with regard to the reactivity of resins and their storage stability were observed when 0.005 wt.- $\%$ of both modifiers were used.

5. With more than ca. $0.30 \mathrm{~mL}$ of cobalt accelerator used per $25 \mathrm{~g}$ of resin the resin reactivity does not improve (i.e. there is no reduction of gelation time), irrespectively of the amount of initiator.

6. By introducing ammonium salt stabilizer (benzyltriethylammonium chloride) to the modified unsaturated polyester resins one can significantly increase their storage (shelf) stability. For both modifiers the presence of ammonium salt changed the reactivity of composition by prolonging the gelation time for resins containing from 0.002 to 0.02 wt.- $\%$ modifiers A from about eight to ten times or between 2 and 3 times for resins containing from 0.05 to $1.50 \mathrm{wt} . \mathrm{-} \%$ and from two to three times for the whole range of used concentrations of the modifier $B$. Again the reactivity depended on the amount of the builtin amine modifier.

\section{References}

1. W. Królikowski, Z. Kłosowska-Wołkowicz, P. Penczek, Polyester resins and laminates (in Polish), WNT, Warsaw 1986, pp. 175-177 and 201-207.

2. A. G. Bayer, Cold-setting Copolymers, GB Patent Number 757,989, date of patent September 26, 1956.

3. P. Z. Li, Plast. Massy, 1961, 12, 11-15. DOI:10.1176/ps.12.5.15

4. Chemische Werke Witten $\mathrm{GmbH}$, Improvements in or relating to hardening of unsaturated polyeter compositions, GB Patent Number 985750, date of patent March 10, 1965.

5. R. Burkhard, H. Wulff, Verfahren zum Haerten von unsaettigte stickstoff- haltige Polyester enthaltende Polyester-Form-massen, DE Patent Number 1196868, date of patent Juli 15, 1965.

6. S. S. Jada, Makromol. Chem. 1982, 183, 1763-1774.

DOI:10.1002/macp.1982.021830716

7. S. S. Jada, C. U. Pittman, Ind. Eng. Chem. Prod. Res. Dev. 1983, 21, 281-284. DOI:10.1021/i300006a017

8. S. S. Jada, Ind. Eng. Chem. Prod. Res. Dev. 1983, 22, 14-19. DOI:10.1021/i300009a005

9. B. Gawdzik, T. Matynia, Method of Preaccelerating Unsaturated Polyester Resins, PL Patent Number 305265, date of patent April 1, 1996.

10. A. Motak, A. Kozak, W. Tarnawski, J. Uzar, T. Podulka, G. Rokosz, Method of Pre-acceleration of Unsaturated Polyester Resins, PL Patent number 354814, date of patent January 12, 2004.

11. J. Reijnders, G. M. Martinus, F. Koers, K. Willem, A. G. Talma, Process for the Preparation an Accelerator Solution, US Patent Number 0011966, date of patent January 9, 2014.

12. H. Kamio, Y. Ogino, K. Nakamura, Accelerated Hardening of Unsaturated Polyester Resins, US Patent Number 4348498, date of patent September 7, 1982.

13. F. Koers, K. Willem, J. Meijer, Accelerator Solution, US Patent Number 120977, date of patent May 5, 2010.

14. F. Koers, K. Willem, A. G. Van de Bovenkamp-Bouwman, Storage-Stable Accelerator Solution, US Patent Number 207841, date of patent August 28, 2008.

15. J. Duliban, Macromol. Mater. Eng. 2001, 286, 624-633. DOI:10.1002/1439-2054(20011001)286:10<624::AID-MA- 
ME624>3.0.CO;2-U

16. M. Kucharski, J. Duliban, E. Chmiel-Szukiewicz, J. Appl. Polym. Sci. 2003, 89, 2973-2976. DOI:10.1002/app.12400

17. J. Duliban, Polimery 2004, 49, 774-779. DOI:10.14314/polimery.2004.774

18. J. Duliban, Macromol. Mater. Eng. 2006, 291, 137-147. DOI:10.1002/mame.200500314

19. J. Duliban, Macromol. Mater. Eng. 2007, 292, 1126-1139. DOI:10.1002/mame.200700146

20. J. Duliban, J. Appl. Polym. Sci. 2011, 120, 311-321. DOI:10.1002/app.33145

21. J. Duliban, J. Appl. Polym. Sci. 2012, 125, 3708-3720. DOI:10.1002/app.36721

22. Unsaturated polyester resins - Test methods - Determination of the acid number, Polish (European) Standards PN-EN ISO 2114:2002 - English version, Ed. Polish Committee for Standardization.

23. Unsaturated polyester resins - Test methods - Determination of gelation time after adding the initiating system at 25 and 80 degrees C, Polish (European) Standards PN-EN ISO 2535:2002 - English version, Ed. Polish Committee for Standardization.
24. Unsaturated polyester resins - Test methods - Determination of durability at elevated temperature, Polish Standard PN-C89082-09: 1986 - Polish version, Ed. Polish Committee for Standardization.

25. Z. Brojer, Z. Hertz, P. Penczek, Epoxy resins, PWN, Warsaw 1972, pp. 448-449.

26. Plastics - Unsaturated polyester resins - Determination of the hydroxyl number, Polish (European) Standards PN-EN ISO 2554:2001 - Polish version, Ed. Polish Committee for Standardization.

27. W. Conrad, Verfahren zum Aushaerten von Polyestermoertel unter Verschiedenen Temperaturbedingungen, DE Patent Number 227711, date of patent October 9, 1984.

28. E. Carleton, N. J. Montclair, Glykol-Maleic Acid Resin and Process of Making Same, US-patent Number 2,195,362, date of patent May 21, 1936.

29. E. Carleton, N. J. Montclair, Ethylenic-Alpha-Beta Synthetic resing and Process of making same, US Patent Number 2,255,313, date of patent September 9, 1941.

30. M. Oleksy, H. Galina, Polimery, 2000, 45, 541-547. DOI:10.14314/polimery.2000.541

\section{Povzetek}

Predstavljamo rezultate sinteze novih modifikatorjev za pripravo nenasičenih poliestrskih smol, ki so nastale $\mathrm{z}$ reakcijo med etilen oksidom ali propilen oksidom ter fenilen-1,2-diaminom. Preučili smo učinek modifikatorjev in kobaltovih pospeševalcev na reaktivnost reakcije tvorbe polimernih smol. Kadar smo amine uporabili v količini do 1.50 utežnega $\%$, so se gelacijski časi za nenasičene modificirane poliestre občutno zmanjšali (za večkrat). Vendar se je povečana reaktivnost odražala na račun zmanjšane stabilnosti smol.

Except when otherwise noted, articles in this journal are published under the terms and conditions of the Creative Commons Attribution 4.0 International License 